\title{
A Solution Method for a Two-Layer Sustainable Supply Chain Distribution Model
}

Validi, S., Bhattacharya, A. \& Byrne, P.J.. 2015. A Solution Method for a Two-Layer Sustainable Supply Chain Distribution Model. COMPUTERS \& OPERATIONS RESEARCH, 54,, pp204-217.

\begin{abstract}
This article presents an effective solution method for a two-layer, NP-hard sustainable supply chain distribution model. A DoE-guided MOGA-II optimiser based solution method is proposed for locating a set of non-dominated solutions distributed along the Pareto frontier. The solution method allows decision-makers to prioritise the realistic solutions, while focusing on alternate transportation scenarios. The solution method has been implemented for the case of an Irish dairy processing industry's two-layer supply chain network. The DoE generates 6,100 real feasible solutions after 100 generations of the MOGA-II optimiser which are then refined using statistical experimentation. As the decisionmaker is presented with a choice of several distribution routes on the demand side of the twolayer network, TOPSIS is applied to rank the set of non-dominated solutions thus facilitating the selection of the best sustainable distribution route. The solution method characterises the Pareto solutions from disparate scenarios through numerical and statistical experimentations. A set of realistic routes from plants to consumers is derived and mapped which minimises total $\mathrm{CO}_{2}$ emissions and costs where it can be seen that the solution method outperforms existing solution methods.
\end{abstract}

Keywords: Sustainable supply chain; Distribution system; Multi-objective mixed-integer programming; Solution method; Design of experiment; MOGA-II optimiser. 


\section{Introduction}

Increased consciousness amongst consumers, firms and governmental organisations towards the escalated deterioration of the environment caused by human actions has significantly increased the momentum in sustainable supply chain management. In reality, in a supply chain (SC) firms are now not only held responsible for themselves but also for the environmental and social performance of their suppliers (Seuring and Müller 2008). In today's competitive environment it is essential that the logistical elements of sustainable-SC networks must operate on a combined platform of reduced carbon emissions and low operating costs. The operation of low-carbon SCs is one of today's most strategic challenges. When designing and developing modern SCs, transportation decisions are of major concern as they have substantial implications on the environmental performance of the SC and additionally the cost of product distribution significantly contributes towards the total SC cost. For this reason, one of the key success parameters presented for improved enterprise performance for local product sales markets is the efficacy of product distribution decisions (Lopes et al. 2008), making low-carbon distribution system design a strategic priority for many businesses.

Carbon dioxide $\left(\mathrm{CO}_{2}\right)$ is one of the six greenhouse gases included in the Kyoto protocol. According to the United Nations Framework Convention on Climate Change (UNFCCC 2012), $\mathrm{CO}_{2}$ is considered as the principal greenhouse gas in the "carbon market". Often the quantity of emitted greenhouse gases is expressed as $\mathrm{CO}_{2}$ equivalent $\left(\mathrm{CO}_{2} \mathrm{e}\right)$ in the carbon footprint. The "total amount of $\mathrm{CO}_{2} e$ emissions that is directly and indirectly caused by an activity or is accumulated over the life stages of a product" is described as the carbon footprint (Wiedmann and Minx 2008). More precisely, $\mathrm{CO}_{2} \mathrm{e}$ gases emitted across a SC for a single unit of a product is referred to as its carbon footprint (Reclay Holding GmbH 2012). Therefore, to enhance the efficiency of green-SC networks it is recommended that the total amount of $\mathrm{CO}_{2}$ e should be evaluated in order to identify mechanisms by which the SC carbon footprint can be reduced. In this article the term "low-carbon" is delineated as a descriptor for the performance associated with a "carbon footprint". A number of recent studies in this domain have reported on the integration of low carbon emission issues with operational decision-making for procurement, production and inventory management (Benjaafar et al. 2013) and on the relevance of carbon footprint taxation schemes, and such studies can have effect on the optimal choice in sourcing decisions (Choi 2013a, 2013b, 2013c).

There are a number of recommended low-carbon/green-SC principles in businesses, such as: the in-depth discernment of the impact of the carbon footprint with manufacturing locations and raw material sources, alternative sourcing options, operating speed of SCs, reduction of the use of packaging, increases in proportional reverse logistics (Grenchus et al. 2011; Alzaman 2014) and the re-design of distribution channels. In a SC network, logistics service providers are required to contribute by increasing SC efficiency while simultaneously reducing associated costs and carbon emissions. Transportation in logistic activities is one of the most significant sources of air pollution and greenhouse gas emissions within a SC (Wang et al. 2011). These activities leave harmful effects on human health and the environment (Salimifard and Raeesi 2014). Therefore, transportation activities of products from plants to 
retailers via roadways warrant more thorough investigation. Minimisation of the traversed distance (Herrero et al. 2014) and maximisation of vehicle utilisation during transportation are potential solutions for emissions reduction. Considering the principles of low-carbon SCs and the effect of transportation activities on society, this article supports the need for a sustainable capacitated distribution model to manage both the carbon footprint and cost on the demand side of a SC.

Several approaches have been considered to date to tackle distribution system problems on the demand-side of SCs. Two-layer distribution system models are well known to be computationally NP-hard. There is no unique solution to these types of models but a feasible solution space. A variety of heuristics/meta-heuristics used to solve such models can be found in the literature in the form of one or multi-phase algorithms. In this article a novel Design of Experiment (DoE)-guided solution method is implemented on a two-layer sustainable distribution system. The DoE guides a Multi-Objective Genetic Algorithm of kind II (MOGA-II) optimiser towards the selection of the best optimal realistic solution sets from a large number of available optimal feasible solutions. The decision-makers' prioritisation is encapsulated in the analysis and subsequent ranking of the realistic solutions using TOPSIS (Hwang and Yoon 1981). The implementation of this efficient solution method as presented in this paper is focused on the case of an Irish dairy manufacturing SC.

This remainder of the article is organised as follows. A comprehensive literature review on distribution system methods and their solution approaches is provided in Section 2. The next section elucidates the holistic solution method for the sustainable distribution system optimisation. In this section the DoE-guided MOGA-II solution method is described and its implementation in an Irish dairy manufacturer's SC discussed. Section 4 delineates the results obtained from the DoE-guided solution method, which are then analysed in Section 5. This section illustrates the final results and discusses the characteristics and efficacy of the solution method. Finally, Section 6 concludes the research indicating the scopes for future research.

\section{Literature Survey}

Distribution decisions consider a number of constraints in order to satisfy the demands of retailers while simultaneously minimising total costs. The total costs include routing costs, fixed costs of the vehicle, fixed costs and operating costs of the facility (Karaoglan et al. 2012). Distribution systems are modelled as NP-hard combinatorial optimisation problems (Nagy and Salhi 2007; Marinakis and Marinaki 2008; Yu et al. 2010). The nature of NP-hard problems is such that the computational effort required for solution attainment grows exponentially with increasing problem size (Erdoğan and Miller-Hooks 2012). Therefore, there is a need for an effective and robust solution method for distribution system models. A detailed survey of different distribution systems can be found in Laporte (1988).

\subsection{Overview of the related methods}

A detailed survey of the product distribution models can be found in Madsen (1983), Min et al. (1998), and Nagy and Salhi (2007). A wide array of distribution models have been 
reported in the literature. A large number of these existing solution approaches are based on distribution system models using meta-heuristic based methods due to their nature. It is recognised that appropriate usage of meta-heuristic based methods brings an optimal balance between diversification and intensification components thereby identifying search regions with high quality solutions. However, often it is difficult to isolate solutions that perform well in the design space but have poor off-design characteristics. This feature, if included correctly, can increase the efficacy of the solution approaches for distribution system models. From the literature it can be seen that a number of distribution system models have been solved using tools such as particle swarm optimisation, tabu search, simulated annealing, greedy randomised adaptive search procedure, variable neighbourhood search algorithms, ant colony optimisation and genetic algorithms. A presentation of these different solution approaches to distribution system models is provided in Table 1.

Table 1: Solution approaches to distribution system models

\begin{tabular}{l|l}
\hline Publications & Solution approaches \\
\hline Marinakis and Marinaki (2008b) & $\begin{array}{l}\text { Hybrid particle swarm optimisation; multiple phase } \\
\text { neighbourhood search - greedy randomized adaptive search } \\
\text { procedure }\end{array}$ \\
\hline Yang and Zi-Xia (2009) & $\begin{array}{l}\text { Sequential and iterative procedure using particle swarm } \\
\text { optimisation }\end{array}$ \\
\hline Liu et al. (2012) & $\begin{array}{l}\text { Multi-objective particle swarm optimisation combined with } \\
\text { grey relational analysis and entropy weight }\end{array}$ \\
\hline Gendreau et al. (1994) & Tabu search heuristic with a generalised insertion procedure \\
\hline Tuzun and Burke (1999) & Two-phase Tabu search algorithm coded in C \\
\hline Chiang and Russell (2004) & Set partitioning approach and tabu search algorithm \\
\hline Melechovský et al. (2005) & $\begin{array}{l}\text { p-median approach to find an initial feasible solution and a } \\
\text { meta-heuristic integrating variable neighbourhood search and } \\
\text { Tabu search to improve the solution }\end{array}$ \\
\hline Albareda-Sambola et al. (2005) & Tabu search metaheuristic solution with CPLEX 6.5 solver \\
\hline Lin and Kwok (2006) & $\begin{array}{l}\text { A combined Tabu search and simulated annealing } \\
\text { metaheuristics }\end{array}$ \\
\hline Caballero et al. (2007) & $\begin{array}{l}\text { Multi-objective combinatorial optimisation based on tabu } \\
\text { search }\end{array}$ \\
\hline Russell et al. (2008) & Reactive Tabu search method based metaheuristics approach \\
\hline Schwardt and Fischer (2009) & A neural network approach based on a self-organising map \\
\hline Lin et al. (2002) & $\begin{array}{l}\text { Metaheuristics approach based on threshold accepting and } \\
\text { simulated annealing }\end{array}$ \\
\hline Wu et al. (2002) & Simulated annealing \\
\hline Yu et al. (2010) & Simulated annealing \\
\hline Stenger et al. (2012) & Simulated annealing \\
\hline Prins et al. (2006a) & Greedy randomised adaptive search procedure \\
\hline Duhamel et al. (2010) & Greedy randomised adaptive search procedure \\
\hline Nguyen et al. (2012) & Greedy randomised adaptive search procedure \\
\hline Ghodsi and Amiri (2010) & Variable neighbourhood search algorithm \\
\hline Derbel et al. (2011) & Variable neighbourhood search algorithm \\
\hline Bell and McMullen (2004) & Ant colony optimisation \\
\hline Bin et al. (2009) & Ant colony optimisation \\
\hline Ting and Chen (2012) & Ant colony optimisation \\
\hline Prins et al. (2006b) & Genetic algorithm \\
\hline Genetic algorithm \\
\hline
\end{tabular}




\begin{tabular}{l|l} 
Zhou and Liu (2007) & Genetic algorithm \\
\hline Marinakis and Marinaki (2008a) & Genetic algorithm \\
\hline Marinakis and Marinaki (2008b) & Genetic algorithm \\
\hline Jin et al. (2010) & Genetic algorithm \\
\hline Karaoglan and Altiparmak (2010) & Genetic algorithm \\
\hline Marinakis et al. (2008) & Honey bees mating optimisation \\
\hline Amador-Fontalvo et al. (2014) & Bacterial metaheuristics \\
\hline
\end{tabular}

From a perusal of the literature on models in this domain it can be observed that Design of Experiment (DoE)-guided solutions has not been reported. DoE, if included has the capacity to guide the meta-heuristic based solution method from its starting point, thus enabling the isolation of solutions that may perform well at the design space but will have poor off-design characteristics. In utilising DoE in the solution procedure of distribution system models it is necessary to explore the design space first, followed by the performance of "rough" optimisation using "search" algorithms based on explored designs, and then finally the refinement of the feasible solutions using a converging algorithm. In this DoE method $N$ (number of individuals) entries are used as the problem's initial population which is also used by the meta-heuristics.

\subsection{Applications of distribution system models}

A wide variety of distribution decision models in various sectors are available in the literature. For example, logistics models have been implemented for small package shippers (Stenger et al. 2012), the shipping industry (Gunnarsson et al. 2006), blood bank location (Or and Pierskalla 1979), newspaper distribution (Jacobsen and Madsen 1980; Madsen 1983), waste collection (Kulcar 1996; Caballero et al. 2007), medical evacuation (Chan et al. 2001), collection, transportation, treatment and disposal of hazardous material (Alumur and Kara 2007), obnoxious facility location-routing (Cappanera et al. 2004), food and drink distribution (Watson-Gandy and Dohrn 1973), and goods distribution (Perl and Daskin 1984, 1985). Lin et al. (2002) report an application of a distribution model to the bill delivery services of a telecommunication service provider based in Hong Kong. A static conversion from the traditional bricks-and-mortar retailing to the hybrid click-and-mortar business model from the perspective of distribution logistics is reported in Aksen and Altinkemer (2008).

\subsection{Sustainable distribution systems}

There also exists a large volume of research on designing for green-SCM (GrSCM). A variety of drivers for implementing GrSCM practices have been reported in the literature (Noci 1997; Guide and Srivastava 1998; Walton et al. 1998; Gungor and Gupta 1999; Rao and Holt 2005; Lee 2008; Walker et al. 2008; Fortes 2009; Diabat and Govindan 2011). The focus of such GrSCM initiatives are categorised (Srivastava 2007) into two types - (i) green product design and (ii) green operations. This article focuses on green operations of SCM from the logistics perspectives. Applications of the reported models and techniques include the fields of green reverse logistics (Grenchus et al. 2001) and SC-network design (Fleischmann et al. 2001; Zhu et al. 2008; Guide and Van Wassenhove 2009; Hong and Yeh 2012). For example, a two-phased heuristic is reported for cost minimisation, cumulative energy demand and waste for a reverse logistics network (Neto et al. 2009). Wang et al. 
(2011) report a multi-objective optimisation model that facilitates a trade-off between the cost factors and the environmental influence. A mixed integer linear programming technique is reported in Erdoğan and Miller-Hooks (2012) for tackling a green-vehicle routing problem, and an optimised solution to a multi-objective distribution problem is reported in Validi, (2014), Validi et al. (2014) and Validi et al. (2012). However, literature on DoE-guided robust and efficient solution methods for low-carbon distribution system models is scant.

This article proposes a DoE-guided MOGA-II optimiser based solution method for the location of a set of non-dominated solutions distributed along the Pareto frontier by tradingoff among the criteria. During the analysis phase of the solution procedure, TOPSIS is applied to rank the set of non-dominated solutions thereby allowing the decision-maker to select the best low-carbon routes. A comprehensive set of numerical and statistical experimentations characterising the Pareto solutions is provided, with disparate scenarios on the demand side of the SC-network. A set of realistic routes from plants to consumers minimising the total $\mathrm{CO}_{2}$ emission during transportation and total costs for operating the plants and serving the realistic routes considering the demand side of SC is derived and then geographically mapped.

\section{Sustainable Distribution Model - Solution Method}

The objectives as defined here for a sustainable two-layer supply chain are minimisation of the sum of carbon emission, i.e., maximising the 'greening' effect, and minimisation of the sum of costs associated with product distribution.

The steps of the solution method are illustrated in Fig. 1. The solution method for the sustainable optimisation model (expressions 1 to 12 of Appendix-A) uses DoE from the starting-point of the solution procedure. DoE is coupled to an optimiser (Fig. 2) in order to avoid solutions that perform well at the design space but have poor off-design characteristics (modeFRONTIER ${ }^{\circledR} 4$ User Manual). The model explores the design space, performs a "rough" optimisation using "search" algorithms based on the designs and refines the feasible solutions using a converging algorithm. The MOGA-II algorithm is used in order to achieve fast Pareto convergence, in executing the low-carbon two-layer model of Validi et al. (2014) and Validi (2014). The solution method (Figs. 1 and 2) work with discrete variables and support geographical selection and directional crossover, implementation of elitism for multiobjective search, enforcement of user defined constraints by objective function penalisation, allowance of generational or steady state evolution and allowance of concurrent evaluation of independent individuals. The $N$ (number of individuals) entries in the DoE are then used as the problem's initial population.

The 'MOGA-II' optimiser is designed for rapid Pareto convergence of the solution. The optimiser considers discrete variables and uses smart multi-search elitism which enables its robustness. The characteristics of MOGA-II support directional crossover and enforce user defined constraints by objective function penalisation. The optimiser allows for steady state evolution while also allowing concurrent evaluation of independent individuals (Poles 2003; Poles et al. 2004; modeFRONTIER ${ }^{\circledR}$ 2008). 


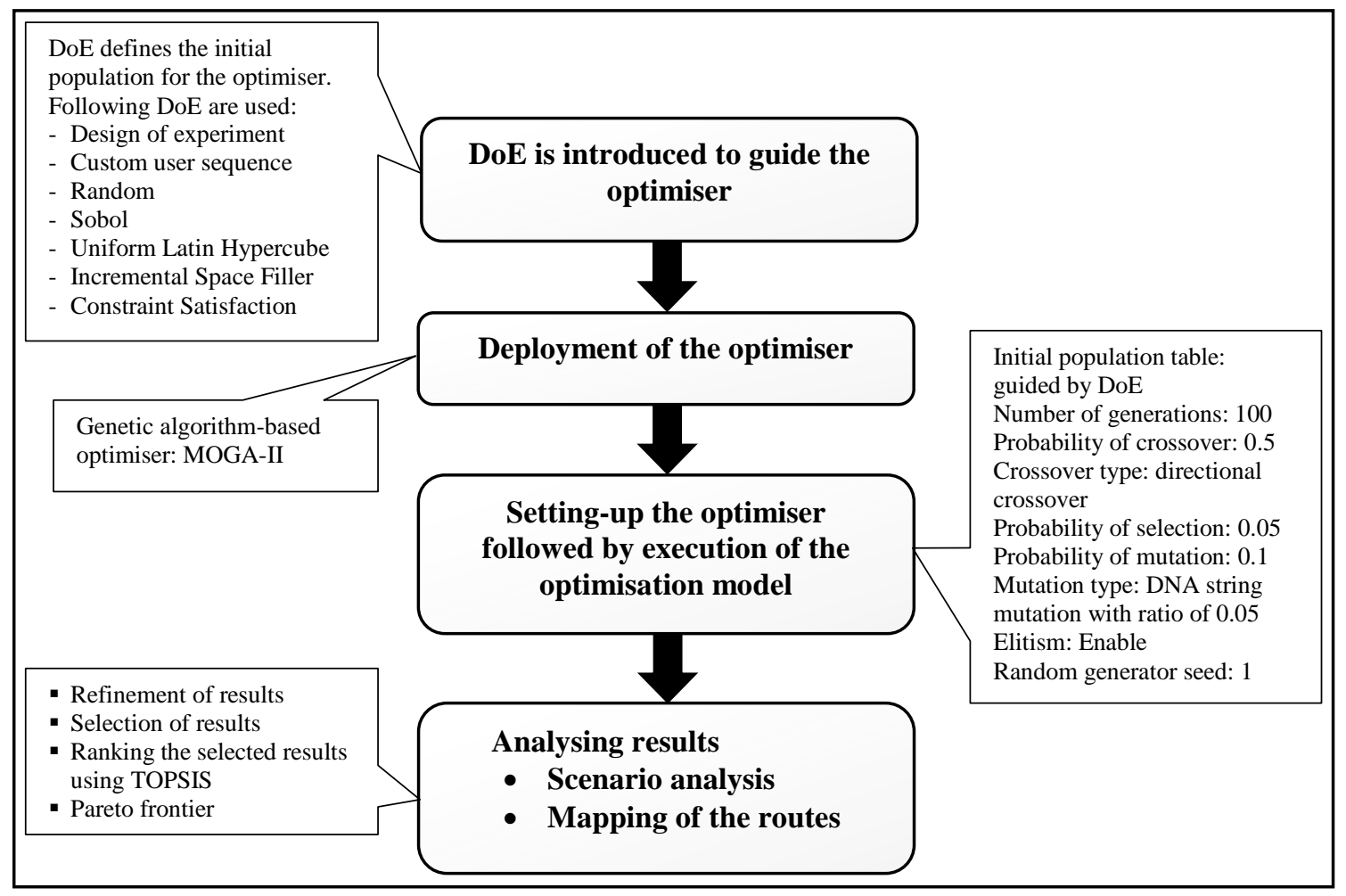

Fig. 1: The steps of the solution method

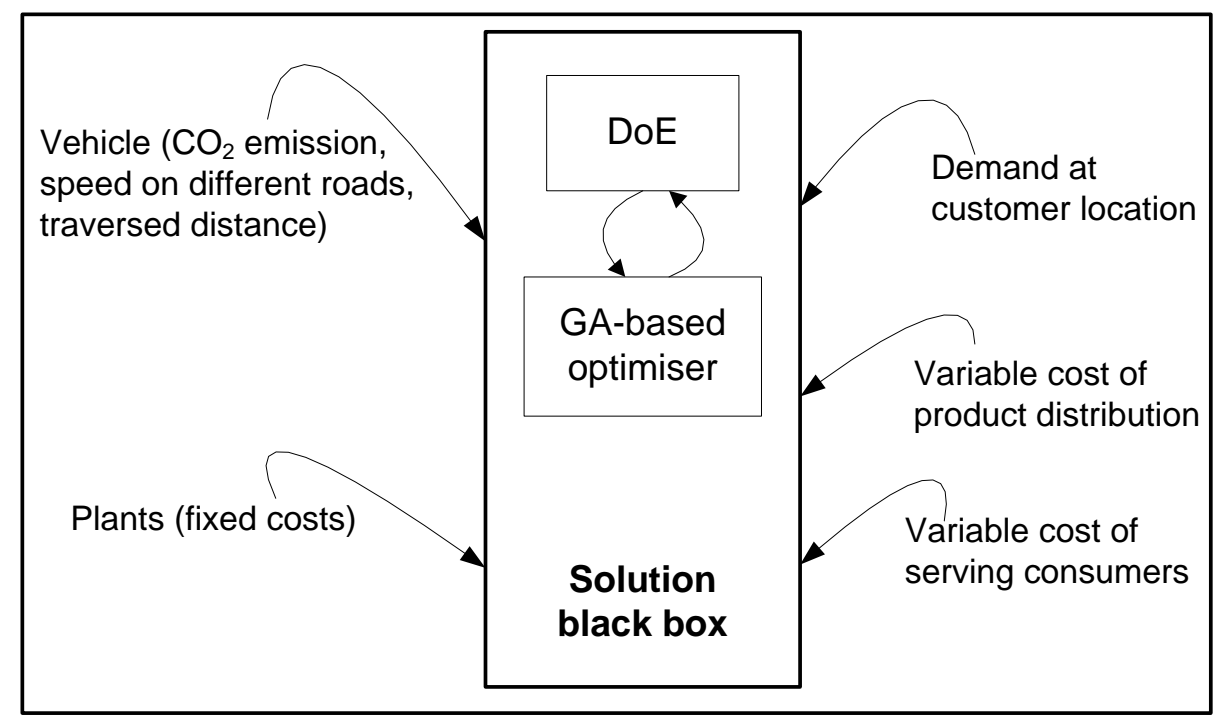

Fig. 2: The black box of the DoE-guided solution method

The sustainable distribution model is a low-carbon multi-objective optimisation model on the demand side of a two-layer supply chain network (Validi et al. 2014; Validi 2014). These two-layers can be plant(s) and distribution centre(s), or plant(s) and customer(s) (Hassanzadeh et al. 2009). The model integrates AHP (Saaty 1977, 1994) with a 0-1 integer programming model. The model minimises $\mathrm{CO}_{2}$ emissions arising from the transportation activities of the products to consumers. Four constraints are considered in the model (Appendix-A). All realistic distribution routes have known start and end points and all the routes are open. The solution method proposed in this article is unique, robust and efficient. 
The AHP-integrated constraint in the optimisation model introduces flexibility in the Decision-Makers' (DM) priorities with respect to the types of vehicles/trucks used for delivering the products from plants to retailers in an environmental-friendly manner. The DMs are asked to compare these vehicles/trucks based on two attributes, namely $\mathrm{CO}_{2}$ emissions and costs. The outcome of the executed procedure results in the $B_{m}$ and $w_{m n}$ matrices of constraint (5) which contribute to the parameters of the objective functions.

The total $\mathrm{CO}_{2}$ emission from the vehicles is estimated. Fuel efficiency is considered as 0.35 $\mathrm{lt} / \mathrm{km}$ based on the report of the Department of Energy and Climate Change, UK (2010) and Nylund and Erkkilä (2005). Guidelines to DEFRA's (2008) greenhouse gas conversion factors are considered in order to compute the cost of serving each of these routes (Validi et al. 2014; Validi 2014).

\section{Case of an Irish Supply Chain}

The sustainable capacitated distribution model is computationally NP-hard. This optimisation model is implemented considering the objective functions and the constraints of the two-layer model in a DoE-guided MOGA-II optimiser.

This unique solution method has been deployed for the low-carbon distribution system considering a case of a dairy market supply chain in the east of Ireland. Milk is a staple of the Irish diet that provides a valuable source of nutrients. According to the Irish Co-operative Organisation Society (ICOS) 52 million people are fed milk globally. Ireland's pasture-based production system makes Irish dairy farming amongst the most efficient in the world maintaining sustainability in all the three levels, viz., environmental, social and economic (ICOS 2012).

The case of the two-layer Irish dairy market supply chain considers two milk processing plants based in Drogheda and Ballitore in the east of Ireland. The primary consumers are located in twenty-two consumer points of the main cities/towns having defined routes connecting those locations. Consumers located at twenty-two different places have been considered within sixteen counties in the east of Ireland. These counties are: Louth, Longford, Meath, West-Meath, Offaly, Kildare, Laois, Wicklow, South Tipperary, North Tipperary, Waterford, Kilkenny, Wexford, Dublin, Monaghan and Cavan. The cost of serving each of these routes is the sum of fuel costs and driver's wage (Validi 2014; Validi et al. 2014). Processing plants and the retailers are on the demand side of this supply chain. The objectives of this low-carbon two-layer SC are to minimise the sum of carbon emission (i.e., maximising 'greening' effect) and the sum of costs associated with transportation.

In order to implement the solution method the following elements are considered: (i) fixed cost of operating plants, (ii) variable costs of at plants, (iii) average speed of a vehicle on a route, (iv) $\mathrm{CO}_{2}$ emission during transportation between the plants and retailers, (v) cost of serving each of the routes between the plants and retailers, (vi) weight matrix for the green constraint and (vii) right-hand side of the green constraint. Fixed cost refers to the total fixed 
costs of operating each plant for a cycle time of 2-3 days. Variable cost refers to the costs required to serve each retailer at each plant. This is related to the demand at the consumption point per unit. One 'unit' refers to a two-litre carton of milk. It is assumed that milk consumption is proportional to the overall population of each of the twenty-two cities/towns located in the sixteen counties and is consider as $2 / 3$ of the population at each location (Validi 2014; Validi et al. 2014).

The vehicles considered for transportation are either refrigerated heavy duty vehicles or heavy goods vehicles. In most countries these are typical of the types of vehicles used to deliver dairy products. Depending on the condition and type of roads disparate speed limits of the vehicles apply. An average speed for each type of road on the routes is considered. Table A1 represents the permissible speed limits stipulated by the 'Road Traffic Act 2004' in Ireland and the average working speeds considered for the vehicles employed in transportation. All vehicles run on Diesel and the volume of burnt Diesel in each path is computed. Average price of Diesel in Ireland during April/May 2012 has been $€ 1.53$ per litre. On average one such vehicle/truck driver's wage is $€ 11.50$ per hour. During April/May 2012 the average wage of a truck driver in Ireland was estimated as stipulated in irishjobs.ie and payscale.com. Speed affects the cost of serving the route. Each route may include a combination of different types of roads. The $\mathrm{CO}_{2}$ emission from a Diesel vehicle (in $\mathrm{kg}$ ) is determined. Table 1 shows the $\mathrm{CO}_{2}$ emission from the burnt fuel for travelling between the plants and the retailers using designated routes. The corresponding cost of serving each route has also been indicated in Table 1 (Validi 2014; Validi et al. 2014).

Table 1: $\mathrm{CO}_{2}$ emission estimations and costs of serving each path by heavy duty trucks from each plant to each retailers

\begin{tabular}{lcccc}
\hline Retailer & \multicolumn{2}{c}{ Plant-I (Drogheda) } & \multicolumn{2}{c}{ Plant-II (Ballitore) } \\
\cline { 2 - 5 } & $\begin{array}{c}\mathrm{CO}_{2} \text { emission from } \\
\text { fuel burnt }(\mathrm{kg})\end{array}$ & $\begin{array}{c}\text { Cost of serving } \\
\text { path }(€)\end{array}$ & $\begin{array}{c}\mathrm{CO}_{2} \text { emission from } \\
\text { fuel burnt }(\mathrm{kg})\end{array}$ & $\begin{array}{c}\text { Cost of serving } \\
\text { path }(€)\end{array}$ \\
\hline 1. Drogheda & 1.85 & 1.84 & 108.11 & 77.70 \\
2. Dundalk & 33.63 & 23.68 & 134.90 & 96.59 \\
3. Navan & 23.84 & 19.75 & 97.02 & 68.30 \\
4. Tullamore & 101.64 & 74.72 & 57.75 & 47.84 \\
5. Naas & 69.67 & 57.72 & 26.89 & 22.28 \\
6. Newbridge & 95.17 & 67.00 & 22.64 & 18.75 \\
7. Leixlip & 43.89 & 36.36 & 56.46 & 39.75 \\
8. Port Laoise & 132.13 & 93.02 & 34.28 & 27.38 \\
9. Bray & 68.93 & 48.53 & 65.97 & 48.50 \\
10. Arklow & 118.27 & 85.29 & 53.22 & 44.09 \\
11. Wicklow & 111.80 & 78.71 & 44.35 & 36.74 \\
12. Greystons & 77.25 & 54.38 & 65.05 & 53.89 \\
13. Clonmel & 208.80 & 147.01 & 102.56 & 73.63 \\
14. Waterford & 202.36 & 142.46 & 97.02 & 68.30 \\
15. Tramore & 214.37 & 150.92 & 108.11 & 76.11 \\
16. Kilkenny & 164.47 & 115.79 & 58.58 & 41.24 \\
17. Wexford & 182.03 & 128.15 & 87.59 & 64.39 \\
18. Ennoscorthy & 170.02 & 124.98 & 66.90 & 52.64 \\
19. Dublin City & 48.42 & 34.09 & 55.25 & 40.62 \\
20. Dun Laogharire / & 58.12 & 40.92 & 61.63 & 45.31 \\
Rathdawn & 26.98 & & 79.00 & \\
21. Fingal & 56.83 & 22.35 & 41.67 & 58.08 \\
22. South Dublin & & 47.08 & & 30.63 \\
\hline
\end{tabular}


The DMs' linguistic preferences for the choice of vehicle types in the SC-network are accounted for in the AHP-integrated constraint. AHP, a multiple-criteria decision-making technique, aids the DMs in decomposing a complicated decision problem into a hierarchical structure with multiple levels of goal, criteria, and alternatives. In order to avoid cumbersome mathematical computational procedures, three types of vehicles/trucks with different levels of $\mathrm{CO}_{2}$ emission and costs are considered. Table 2 illustrates the types of vehicles corresponding to their level of $\mathrm{CO}_{2}$ emission and costs using linguistic preferences. The DMs have been asked to compare the available vehicles based on the two attributes. AHP translates the linguistic preferences of DMs and vehicle comparison matrices are constructed based on the linguistic preferences of the DMs.

Table 2: Types of the vehicles (Validi 2014; Validi et al. 2014)

\begin{tabular}{lll}
\hline & $\mathbf{C O}_{2}$ emission & Costs \\
\hline Vehicle type 1 $\left(\mathbf{T}_{1}\right)$ & Medium & Medium \\
Vehicle type 2 $\left(\mathbf{T}_{2}\right)$ & Low & High \\
Vehicle type 3 $\left(\mathbf{T}_{3}\right)$ & High & Low \\
\hline
\end{tabular}

DMs have used the spatial criteria with degree of importance of 1 to 9 (Saaty 1977), 1 being equal importance and 9 being absolute importance, to compare the vehicle types. Following the execution of the formal AHP steps of the weight matrix (Table 3) was found.

Table 3: $w_{m n}$ matrix for vehicle types (Validi 2014; Validi et al. 2014)

\begin{tabular}{lcccl}
\hline & $\mathbf{T}_{\mathbf{1}}$ & $\mathbf{T}_{\mathbf{2}}$ & $\mathbf{T}_{\mathbf{3}}$ & Sum of weights \\
\hline $\mathbf{C O}_{\mathbf{2}}$ emission & 0.33 & 0.24 & 0.43 & 1.00 \\
Costs & 0.32 & 0.43 & 0.25 & 1.00 \\
\hline
\end{tabular}

As there is no standard limit for $\mathrm{CO}_{2}$ emission for heavy duty vehicles in Ireland, the minimum and maximum amount of $\mathrm{CO}_{2}$ emission and costs found from Table 1 is considered as the right-hand side matrix values of the green constraint: $B_{m}=\left(\begin{array}{c}108 \\ 76\end{array}\right)$. There can be situations when the values of the left hand side matrix of the AHP constraint-(5) are greater than the right hand side matrix values. In such cases those vehicles responsible for creating these greater values will not be chosen, although they are eligible in all other criteria.

\subsection{DoE-guided MOGA-II execution}

The DoE-guided MOGA-II is executed in order to locate a set of non-dominated solutions distributed along the Pareto frontier by way of trading-off among the criteria for the combinatorial optimisation model. $N$ entries (i.e., number of individuals) in the DoE are used as the problem's initial population. Population in the DoE results in 61 different designs. DoE based on a custom user sequence generates 15 designs while there are another 15 random designs based on a random sequence with a uniform distribution. This random design is used as an initial design population for MOGA-II. DoE based on a pseudo random Sobol sequence generates 10 designs. It works best with 2 to 20 variables. These experiments are uniformly distributed in the design space. Next, DoE based on the Latin Hypercube samplings contributes to 10 designs in the DoE population. In this design the points are randomly and 
uniformly distributed for each variable. Uniform Latin Hypercube is useful when a random sample is needed. It guarantees to be relatively uniformly distributed over each dimension. Another design, known as incremental space filler, generates 10 designs implementing the maximin criterion. The last design in the DoE contains 61 designs by way of constraint satisfaction with an assignment to each variable so that all constraints are satisfied in the constraint satisfaction approach. Based on the DoE table, the optimisation model is executed that results in 6,100 real feasible solutions in 100 generations. The setting details of the multiobjective genetic algorithm are appended to below:

Initial population size: 51
Maximum population size: 6100 (set on 100 generations)
Crossover probability: 0.5
Mutation probability: 0.1
Crossover type: Directional crossover
Mutation type: DNA string mutation with the ratio of 0.05

The refinement procedure of the initial DoE table comprising 61 different designs is explained in Table 4. Based on the initial DoE table the MOGA-II optimiser generates 6,100 feasible solutions which are included in the 'results table'. The 'realistic results table' refines this 'results table' and results in only 2,464 realistic results. Selected results are based on the two lower-most rows in the 4D bubble plot. Box-whiskers fail to guide in selection process as those plots indicate only the densest area of solution space. Sixty realistic designs are selected from the designs table for further evaluation through TOPSIS.

Table 4: Statistical summary on results tables

\begin{tabular}{lccccc}
\hline Type of results & $\begin{array}{l}\text { Number of real } \\
\text { feasible results }\end{array}$ & \multicolumn{2}{c}{$\mathbf{C O}_{2}$ emission } & \multicolumn{2}{c}{ Costs } \\
\cline { 3 - 6 } & 6,100 & Min & Max & Min & Max \\
\hline Results table & 2,464 & 1,175 & 2,309 & 185,948 & 298,547 \\
Realistic results table & 60 & 1,175 & 2,239 & 185,948 & 298,547 \\
Selected results table & & & 2,047 & 185,948 & 249,985 \\
\hline
\end{tabular}
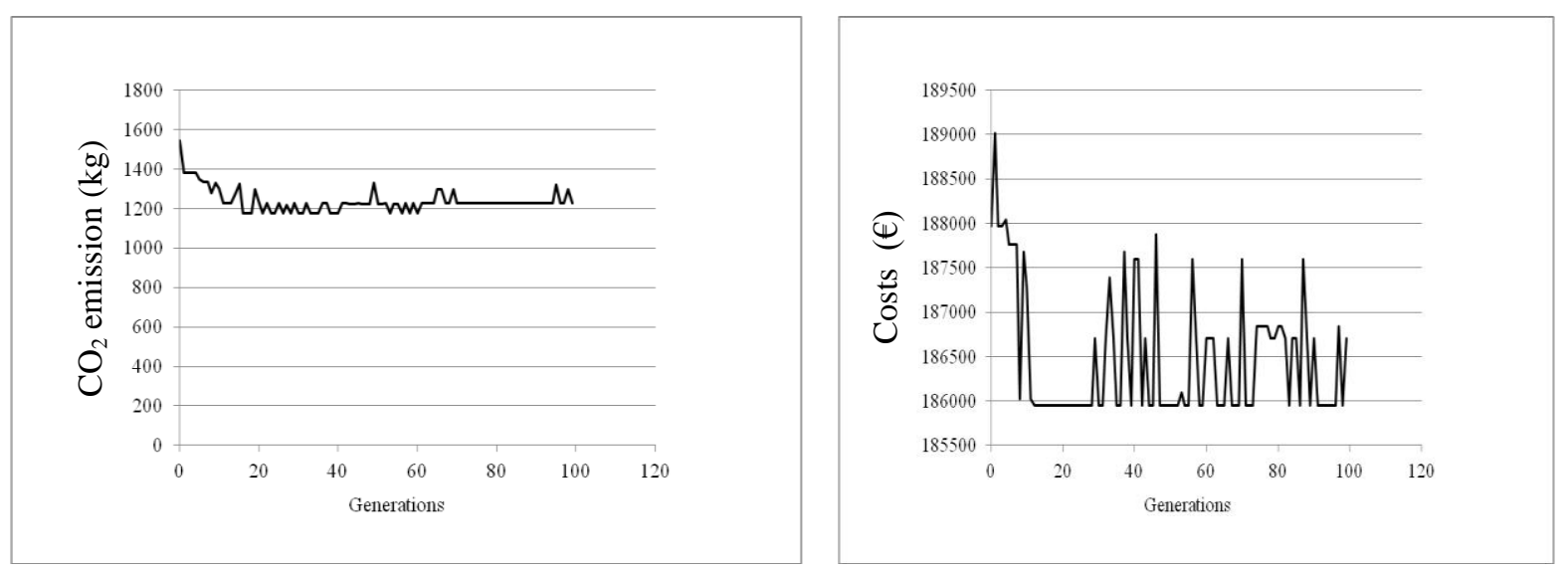
Fig. 3: Performance indicators for a) $\mathrm{CO}_{2}$ and b) costs in the MOGA-II optimiser

Evolutionary search is a stochastic and dynamic process. Therefore, the performance of such a search can be measured using a convergence graph. The optimisation performance of the low-carbon distribution model is determined by two indicators, viz., $\mathrm{CO}_{2}$ emission versus number of generations and costs versus number of generations in MOGA-II. Fig. 3 presents two typical convergence plots of 100 independent runs of MOGA-II with different sets of criteria. It is noticed that after about 20 generations MOGA-II starts converging with less fluctuations.

The MOGA-II optimiser generates a feasible space of solutions with bubble plots. The diameters of these bubbles indicate the identity (ID) numbers as set out in the DoE table. Small bubbles indicate low ID numbers while large bubbles indicate high ID numbers. The colour schemes for the feasible, infeasible solutions and solutions with error are indicated in the legends of the bubble plots. Fig. 4 is a bubble plot elucidating the characteristics of the $\mathrm{CO}_{2}$ emission and costs with reference to IDs and objective function values on realistic results tables that includes 2464 realistic solutions.

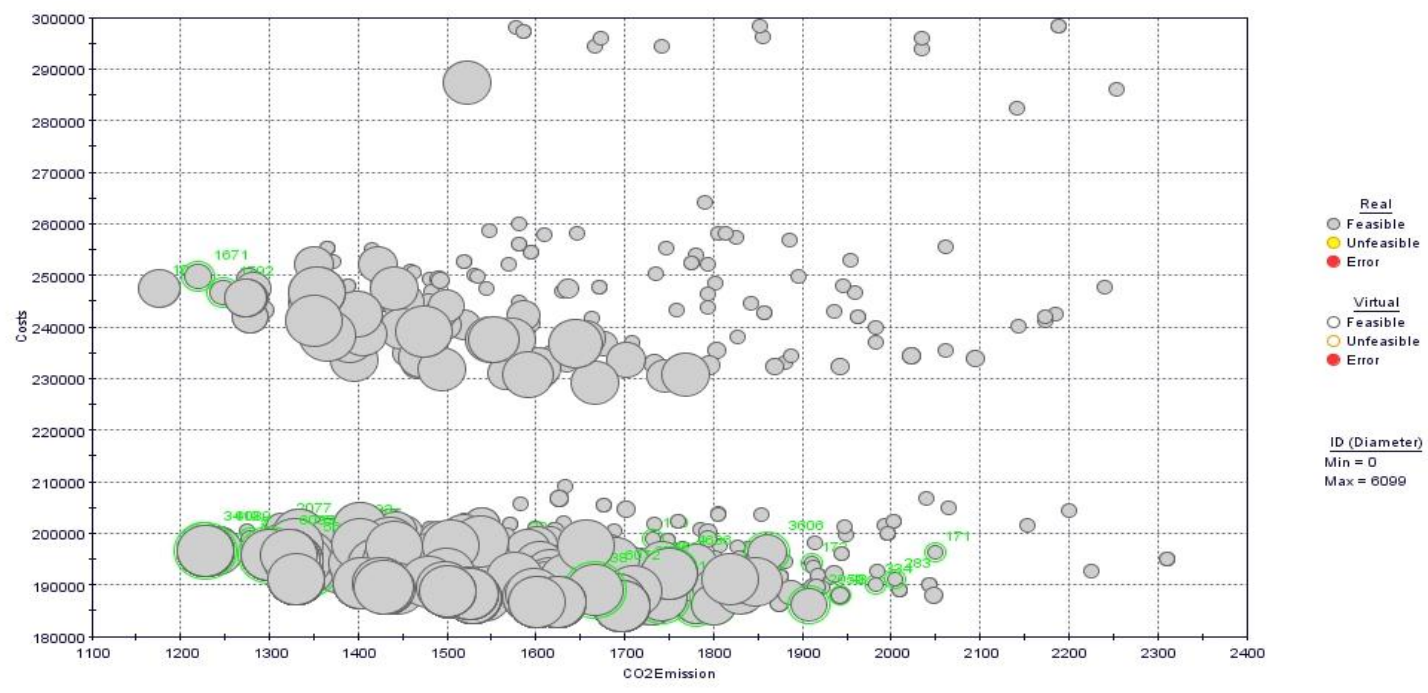

Fig. 4: Costs vs. $\mathrm{CO}_{2}$ bubble plot with reference to IDs on the realistic results table

\subsection{Determination of realistic feasible alternative vehicle routes}

To analyse and evaluate the realistic results, 60 out of the 2,464 realistic solutions are selected. This selection is not random. Initially Box-whiskers for $\mathrm{CO}_{2}$ (Fig. 5) and costs (Fig. 6 ) are considered to select the designs for evaluation. However, Box-whiskers only focus on the densest area which ignores other distinctly visible optimum solutions for each objective function. 


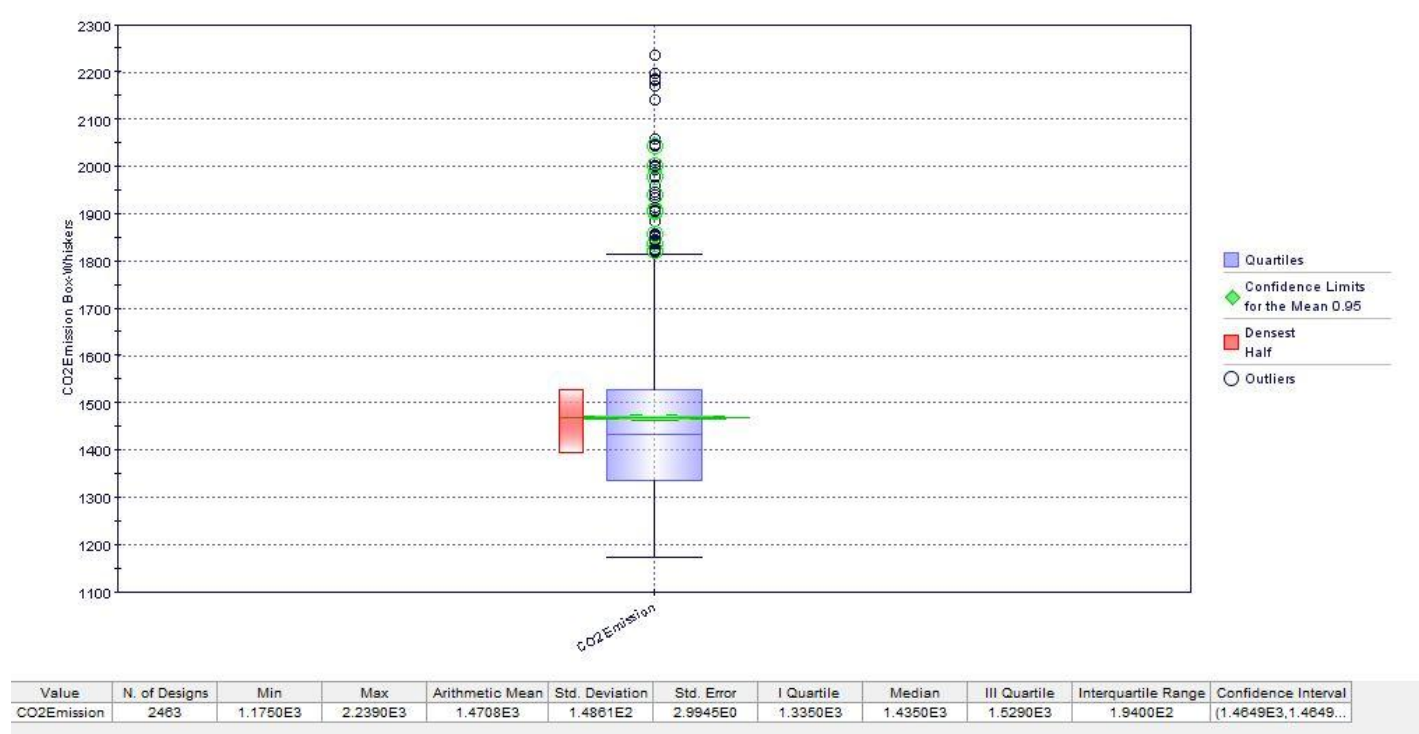

Fig. 5: Box-whisker for $\mathrm{CO}_{2}$ emission on the realistic designs table

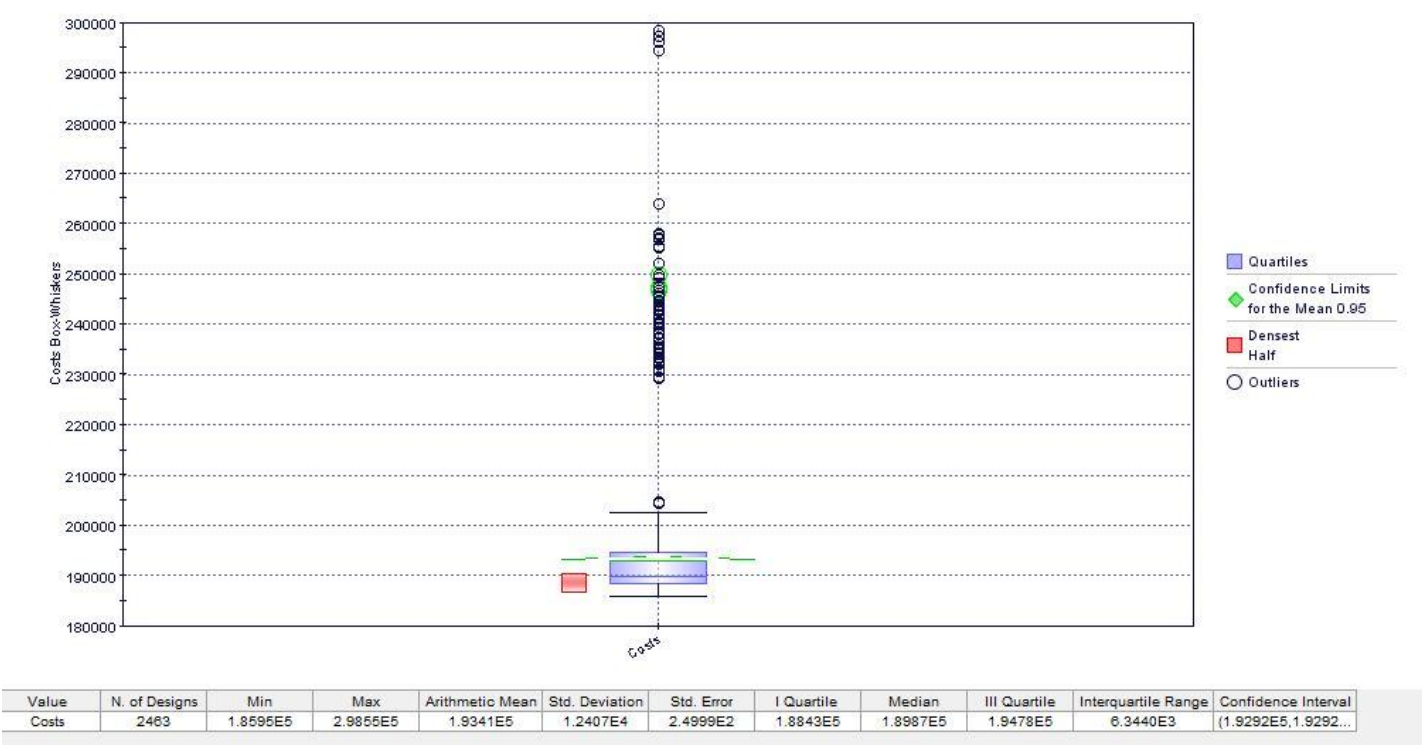

Fig. 6: Box-whisker for costs on the realistic designs table

A selection of un-biased realistic solutions is made from the results table representing 4D bubble plots in Fig. 7 and Fig. 8. It is understood from these figures that the red coloured top layer solutions are not realistic in nature as those involve high cost with high $\mathrm{CO}_{2}$ emission. Therefore, selection is confined to the first two layers of optimum realistic solutions. The selected solutions are indicated by green circles in Figs. 7 and 8. In these diagrams F2 indicates the cost objective function while $\mathrm{F} 1$ denotes $\mathrm{CO}_{2}$ emission. Fig. 7 presents the range of F2 values in colour codes with varying diameters of the bubbles indicating F1 values. Fig. 8 presents the range of $\mathrm{F} 1$ values in colour codes with varying diameters of the bubbles indicating F2 values. 


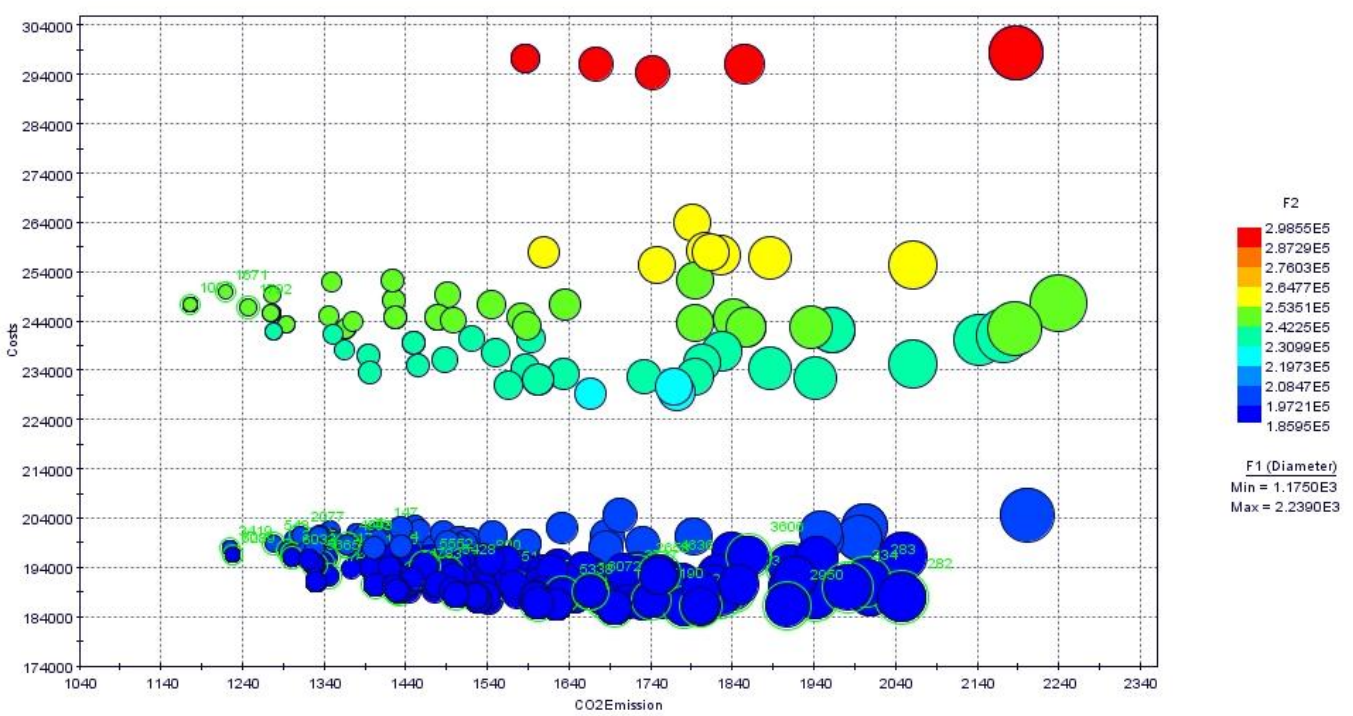

Fig. 7: $\mathrm{CO}_{2}$ vs. costs bubble plot w.r.t. F2 objective function on the realistic results table

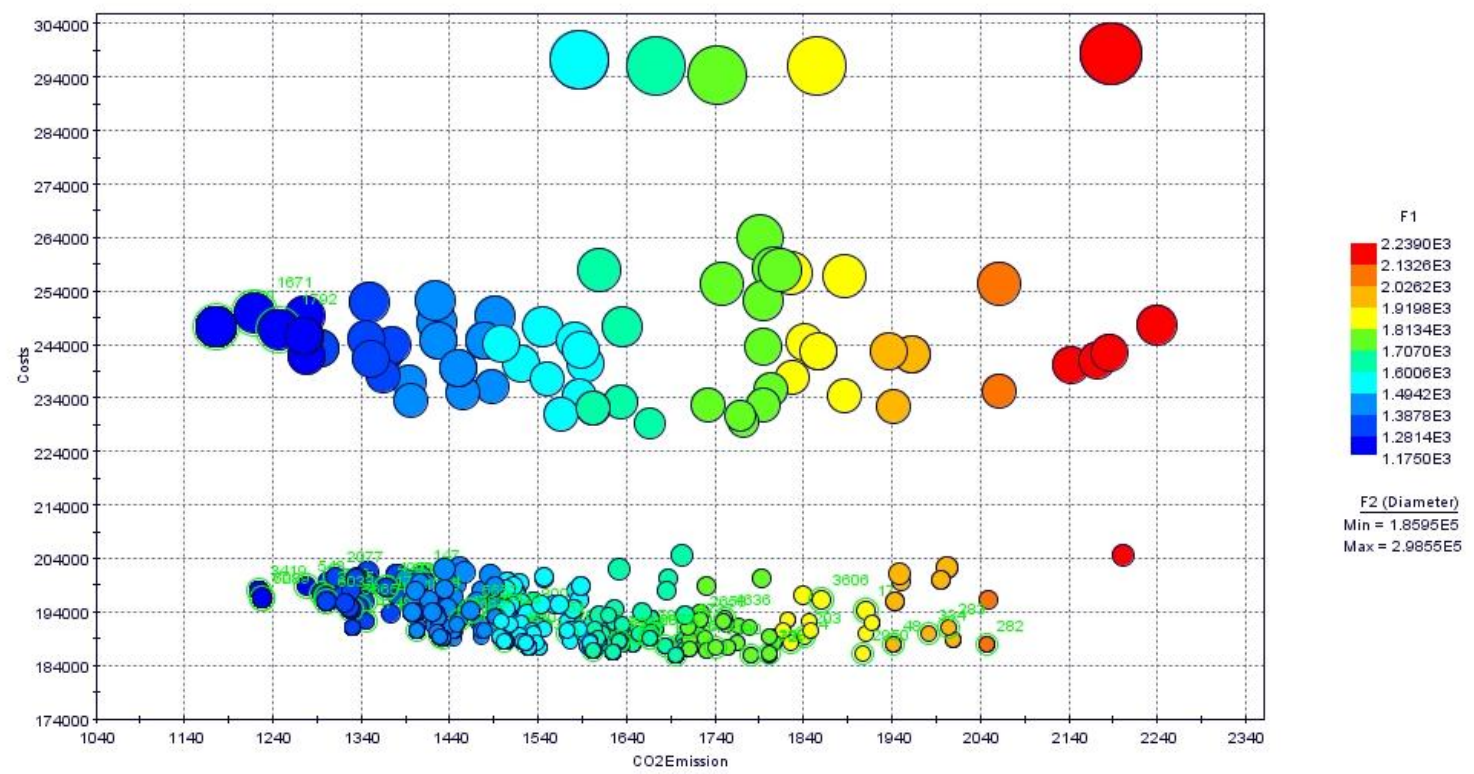

Fig. 8: $\mathrm{CO}_{2}$ vs. costs bubble plot w.r.t $\mathrm{F} 1$ objective function on the realistic results table

Fig. 9 and Fig. 10 show the selected optimal solutions for further evaluation using TOPSIS. Fig. 9 presents the range of F2 values in colour codes with varying diameters of bubbles indicating F1 values. Fig. 10 illustrates the range of F1 values in colour codes with varying diameters of the bubbles indicating F2 values. Green colours around the bubbles indicate result IDs. As shown in Figs. 9 and 10, blue bubbles represent the alternatives with lowest values satisfying both the objective functions of the optimisation problem. 


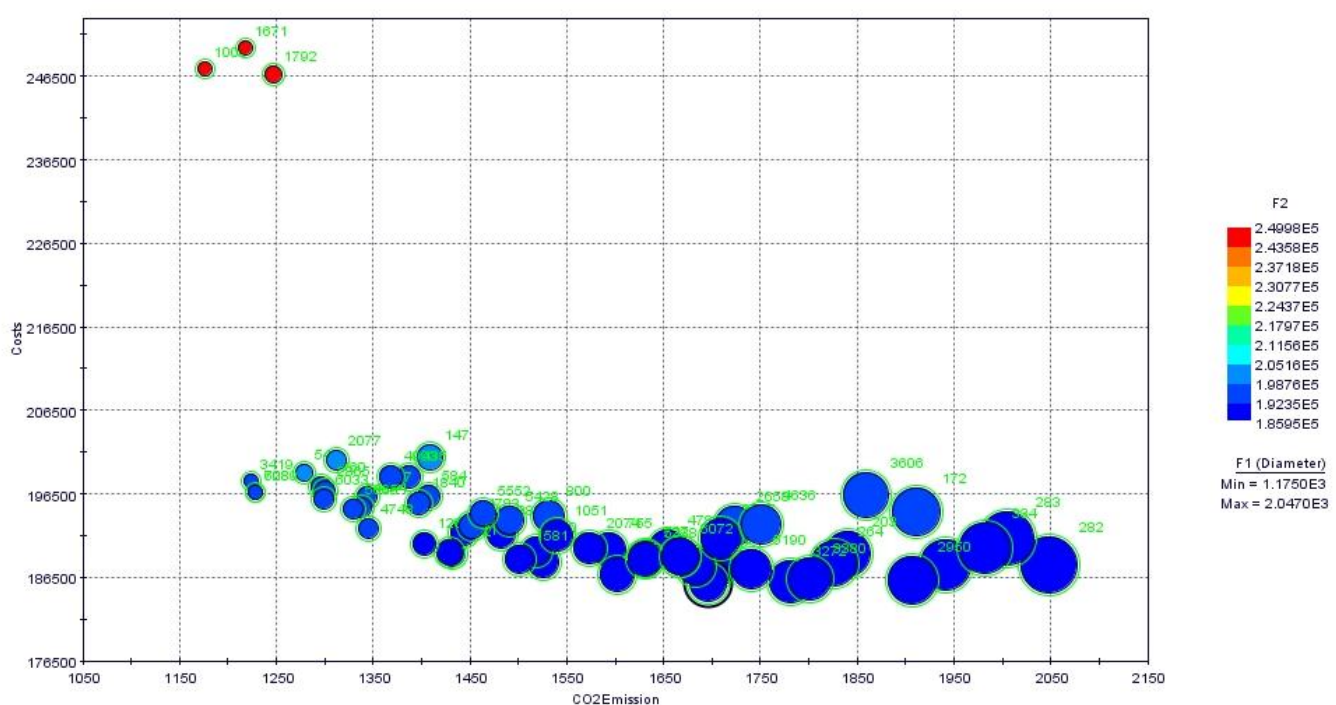

Fig. 9: 4D bubble plot representing selected $\mathrm{CO}_{2}$ vs. costs w.r.t. F2 values

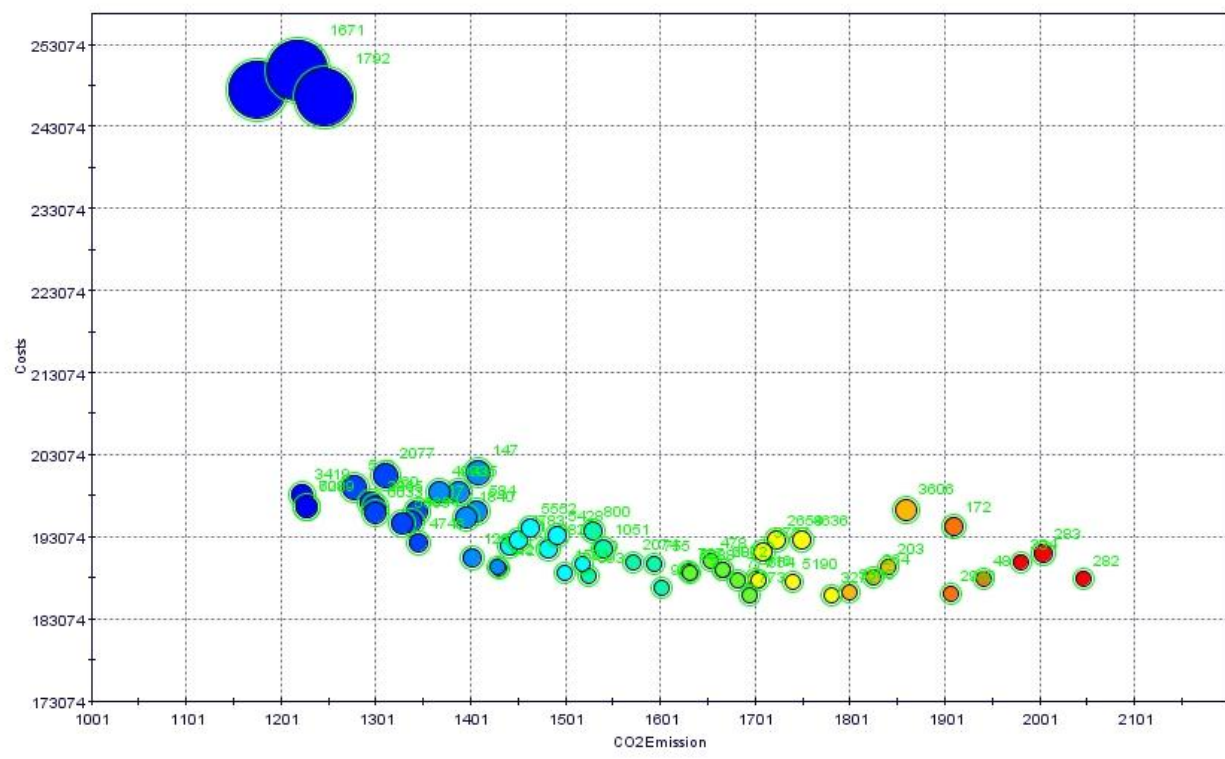

Fig. 10: $4 \mathrm{D}$ bubble plot representing selected $\mathrm{CO}_{2}$ vs. Costs w.r.t. F1 values 


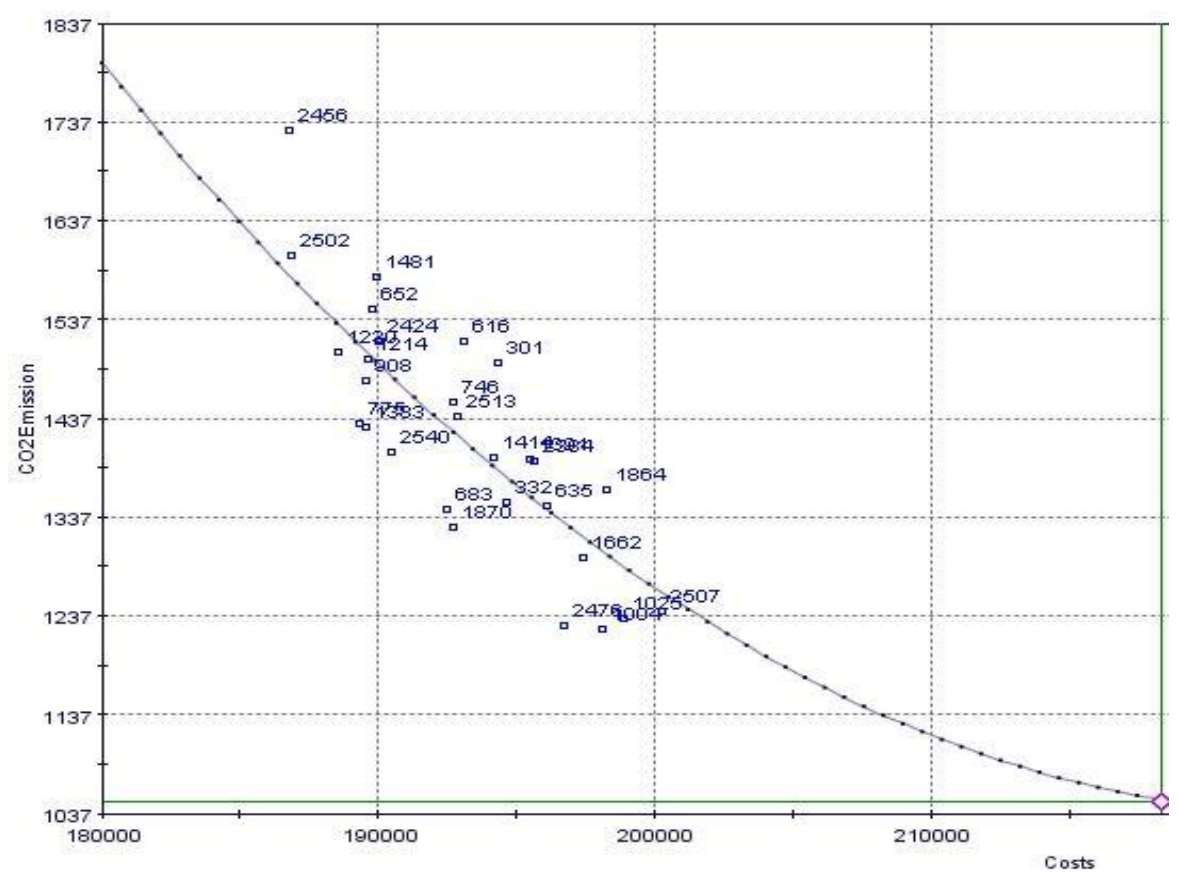

Fig. 11: Pareto frontier on the selected realistic results

Pareto efficiency of the solutions is examined (Fig. 11) in order to evaluate the performance of the DoE-guided MOGA-II optimiser on the selected set of solutions. Pareto efficiency of the selected results (from Table 4) is separately examined. It is found that the selected results are Pareto optimal. The Pareto frontier does not include two results out of the selected results. These two results represent extreme decision-making situations. Therefore, these two results are not considered for further analysis of the optimal solutions using TOPSIS.

\section{Evaluation of the Selected Realistic Feasible Alternative Vehicle Routes}

As low-carbon product distribution decision is a strategic decision-making procedure within the demand side of a supply chain, the set of selected feasible optimal solutions are ranked according to DMs' priorities in order to facilitate the decision-making process. TOPSIS (Hwang and Yoon 1981) is utilised for evaluating the selected feasible optimal solutions obtained. A decision matrix is generated using the results of sixty selected designs with two attributes. These attributes are the objective functions, viz., $\mathrm{CO}_{2}$ emission and total costs. Table B1 in Appendix-B illustrates the generated decision-matrix for TOPSIS.

The decision-makers provide two different weights for the attributes, viz., preferred importance on $\mathrm{CO}_{2}$ emission $\left(W_{a}\right)$ and preferred importance on costs $\left(W_{b}\right)$. These weights are shown in the following matrix:

$\begin{array}{ccc} & \mathrm{CO}_{2} & \text { Costs } \\ W_{a} & 0.60 & 0.40 \\ W_{b} & 0.20 & 0.80\end{array}$


Execution of TOPSIS generates a table of priorities considering $W_{a}$ and $W_{b}$. The ranks of the selected candidate-solutions are illustrated in Table B2 in Appendix-B. The weight $W_{a}$ represents a situation that the DM believes minimising $\mathrm{CO}_{2}$ emission is more important and $W_{b}$ represents a situation that minimisation of costs is more important to the DM. Different alternatives are suggested based on two weight matrices. Details of each of the first three selected designs by TOPSIS using both weight matrices are shown in Table 5.

Table 5: Six selected alternatives in terms of routing pattern from plants to retailers using TOPSIS

\begin{tabular}{|c|c|c|c|c|c|c|}
\hline \multirow[t]{2}{*}{ Alternative vehicle routes } & \multicolumn{6}{|c|}{ Result IDs } \\
\hline & ID-19 & ID-44 & ID-12 & ID-30 & ID-15 & ID-29 \\
\hline V1I & 1 & 1 & 1 & 1 & 1 & 1 \\
\hline V1II & 0 & 0 & 0 & 0 & 0 & 0 \\
\hline V2I & 1 & 1 & 1 & 1 & 0 & 1 \\
\hline V2II & 0 & 0 & 0 & 0 & 1 & 0 \\
\hline V3I & 1 & 1 & 1 & 1 & 1 & 1 \\
\hline V3II & 0 & 0 & 0 & 0 & 0 & 0 \\
\hline V4I & 0 & 0 & 1 & 0 & 0 & 0 \\
\hline V4II & 1 & 1 & 0 & 1 & 1 & 1 \\
\hline V5I & 0 & 0 & 0 & 0 & 0 & 0 \\
\hline V5II & 1 & 1 & 1 & 1 & 1 & 1 \\
\hline V6I & 1 & 0 & 0 & 1 & 0 & 0 \\
\hline V6II & 0 & 1 & 1 & 0 & 1 & 1 \\
\hline V7I & 1 & 1 & 1 & 1 & 1 & 1 \\
\hline V7II & 0 & 0 & 0 & 0 & 0 & 0 \\
\hline V8I & 0 & 0 & 0 & 0 & 0 & 1 \\
\hline V8II & 1 & 1 & 1 & 1 & 1 & 0 \\
\hline V9I & 0 & 0 & 0 & 0 & 0 & 0 \\
\hline V9II & 1 & 1 & 1 & 1 & 1 & 1 \\
\hline V10I & 0 & 0 & 0 & 0 & 0 & 0 \\
\hline V10II & 1 & 1 & 1 & 1 & 1 & 1 \\
\hline V11I & 0 & 0 & 0 & 0 & 0 & 0 \\
\hline V11II & 1 & 1 & 1 & 1 & 1 & 1 \\
\hline V12I & 0 & 0 & 0 & 0 & 0 & 0 \\
\hline V12II & 1 & 1 & 1 & 1 & 1 & 1 \\
\hline V13I & 0 & 0 & 0 & 0 & 0 & 0 \\
\hline V13II & 1 & 1 & 1 & 1 & 1 & 1 \\
\hline V14I & 0 & 0 & 0 & 0 & 0 & 0 \\
\hline V14II & 1 & 1 & 1 & 1 & 1 & 1 \\
\hline V15I & 0 & 0 & 0 & 0 & 0 & 0 \\
\hline V15II & 1 & 1 & 1 & 1 & 1 & 1 \\
\hline V16I & 0 & 0 & 0 & 0 & 0 & 0 \\
\hline V16II & 1 & 1 & 1 & 1 & 1 & 1 \\
\hline V17I & 0 & 0 & 0 & 0 & 0 & 0 \\
\hline V17II & 1 & 1 & 1 & 1 & 1 & 1 \\
\hline V18I & 0 & 0 & 0 & 1 & 1 & 1 \\
\hline V18II & 1 & 1 & 1 & 0 & 0 & 0 \\
\hline V19I & 1 & 1 & 0 & 1 & 1 & 1 \\
\hline V19II & 0 & 0 & 1 & 0 & 0 & 0 \\
\hline V20I & 0 & 1 & 0 & 0 & 0 & 0 \\
\hline V20II & 1 & 0 & 1 & 1 & 1 & 1 \\
\hline V21I & 0 & 0 & 0 & 0 & 0 & 0 \\
\hline V21II & 1 & 1 & 1 & 1 & 1 & 1 \\
\hline
\end{tabular}




\begin{tabular}{|c|c|c|c|c|c|c|c|}
\hline V22I & & 0 & 0 & 0 & 0 & 0 & 0 \\
\hline V22II & & 1 & 1 & 1 & 1 & 1 & 1 \\
\hline $\mathbf{T}_{1}$ & & 1 & 0 & 0 & 1 & 0 & 0 \\
\hline $\mathbf{T}_{2}$ & & 0 & 1 & 0 & 0 & 0 & 0 \\
\hline $\mathbf{T}_{3}$ & & 0 & 0 & 1 & 0 & 1 & 1 \\
\hline $\mathrm{CO}_{2}$ emission & & 1,227 & 1,223 & 1,278 & 1,402 & 1,431 & 1,428 \\
\hline Costs & & 196,705 & 198,141 & 199,099 & 190,505 & 189,330 & 189,523 \\
\hline \multirow{4}{*}{$\begin{array}{c}\text { TOPSIS } \\
\text { priorities }\end{array}$} & \multirow{2}{*}{$W_{a}$} & 0.9179 & 0.9147 & 0.8673 & & & \\
\hline & & 1 & 2 & 3 & & & \\
\hline & \multirow{2}{*}{$W_{b}$} & & & & 0.8819 & 0.8803 & 0.8801 \\
\hline & & & & & 1 & 2 & 3 \\
\hline
\end{tabular}

The ranked results are then implemented. Three examples of the implemented results with disparate mapped scenarios are illustrated in Fig. 12. The realistic product distribution routes from the plants to retailers with low $\mathrm{CO}_{2}$ emission and total costs are mapped.

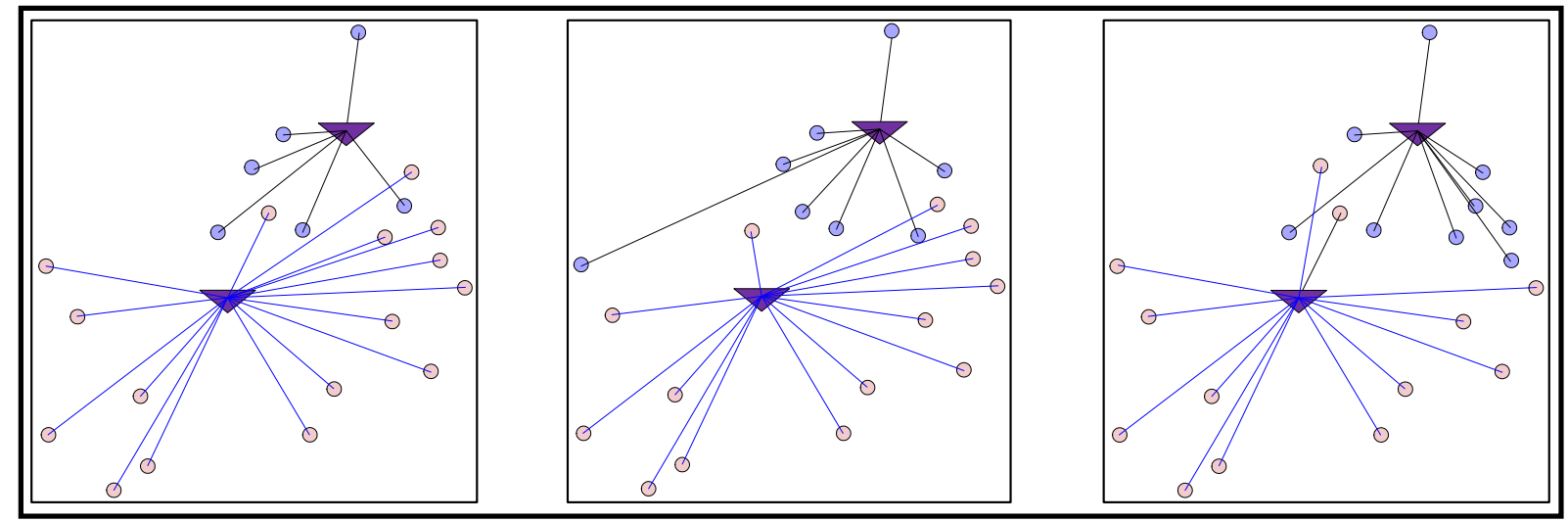

Fig. 12: Sample scenarios of the sustainable distribution routes for different solution IDs

\section{Conclusions}

This article provides a robust solution method to a sustainable NP-hard combinatorial optimisation problem for the demand side of a distribution system of a supply chain using a DoE-guided MOGA-II optimiser-based solution method. The DoE-guided method is implemented for the case of an Irish dairy processing industry's two-layer SC-network. The optimisation model explicitly considers green issues through the constraint and objective function. The DoE-guided method is executed to locate a set of non-dominated solutions distributed along the Pareto frontier by trading-off multiple criteria. A number of populations are considered in the DoE which generates different results. The NP-hard optimisation model is executed in conjunction with the DoE and results in 6,100 real feasible solutions after 100 generations of the MOGA-II optimiser. Refinement of the DoE-guided solution is performed using statistical experimentation. The realistic solutions provide the DMs with several choices for distribution routes on the demand side of the two-layer supply chain network. The efficacy of the solution method is examined through a set of non-dominated solutions distributed along the Pareto frontier by trading-offs in the criteria responsible for the decision. TOPSIS aids in prioritising the realistic low-carbon distribution routes. The generated solution fortifies the strategic decision in the design of a low-carbon supply chain network by minimising both the total cost of operating facilities (i.e., plants) and total carbon emissions. 
The immediate outcome of the proposed solution method results in realistic optimised routes from 'plants' to 'consumers' while minimising the $\mathrm{CO}_{2}$ emission from transportation, and the sum of costs for operating these plants and serving these routes. A set of realistic routes from plants to consumers with minimum total $\mathrm{CO}_{2}$ emission and total costs are then geographically mapped.

The proposed solution method can be extended to a more complex multi-layered distribution model. Performance investigation of the solution method with other optimisers, e.g., Nondominated Sorting Genetic Algorithm-II (NSGA-II), Multi Objective Simulated Annealing (MOSA), Multi-Objective Particle Swarm Optimisation (MOPSO) and Multi-Objective scheduler based on Screening Analysis and Genetic Algorithm (SAnGeA), is recommended. Use of other multi-attribute decision-making tools, viz. ELECTRE, in the analysis method of the results may be investigated as a future scope of this research.

Acknowledgement: This article has been developed as part of a funded $\mathrm{PhD}$ project in the 'Management Group' in Dublin City University Business School. The authors sincerely convey their heartfelt thanks to the anonymous reviewers for their valuable comments which have helped to improve the quality of the paper.

\section{References}

Aksen, D. and Altinkemer, K., 2008. A location-routing problem for the conversion to the "click-and-mortar" retailing: the static case. European Journal of Operational Research, 186(2), 554-575.

Albareda-Sambola, M., Diaz, J.A. and Fernández, E., 2005. A compact model and tight bounds for a combined location-routing problem. Computers \& Operations Research, 32(3), 407-428.

Alumur, S. and Kara, B.Y., 2007. A new model for the hazardous waste location-routing problem. Computers \& Operations Research, 34(5), 1406-1423.

Alzaman, C., 2014. Green supply chain modelling: literature review. International Journal of Business Performance and Supply Chain Modelling, 6(1), 16-39.

Amador-Fontalvo, J.E., Paternina-Arboleda, C.D. and Montoya-Torres, J.R., 2014. Solving the heterogeneous vehicle routing problem with time windows and multiple products via a bacterial meta-heuristic. International Journal of Advanced Operations Management, 6(1), 81-100.

Bell, J.E. and McMullen, P.R., 2004. Ant colony optimization techniques for the vehicle routing problem. Advanced Engineering Informatics, 18(1), 41-48.

Benjaafar, S., Li, Y. and Daskin, M., 2013. Carbon footprint and the management of supply chains: insights from simple models. IEEE Transactions on Automation Science and Engineering, 10(1), 99-116. 
Berger, R.T., 1997, Location-routing models for distribution system design. Ph.D. dissertation, Department of Industrial Engineering and Management Sciences, Northwestern University, Evanston, IL.

Bin, Y., Zhong-Zhen, Y. and Baozhen, Y., 2009. An improved ant colony optimization for vehicle routing problem. European Journal of Operational Research, 196(1), 171-176.

Caballero, R., González, M., Guerrero, F.M., Molina, J. and Paralera, C., 2007. Solving a multiobjective location routing problem with a metaheuristic based on tabu search. Application to a real case in Andalusia. European Journal of Operational Research, 177(3), 1751-1763.

Cappanera, P., Gallo, G. and Maffioli, F., 2004. Discrete facility location and routing of obnoxious activities. Discrete Applied Mathematics, 133(1-3), 3-28.

Chan, Y., Carter, W.B. and Burnes, M.D., 2001. A multiple-depot, multiple-vehicle, locationrouting problem with stochastically processed demands. Computers and Operations Research, 28(8), 803-826.

Chiang, W.C. and Russell, R.A., 2004. Integrating purchasing and routing in a propane gas supply chain. European Journal of Operational Research, 154(3), 710-729.

Choi, T.-M., 2013a. Local sourcing and fashion quick response system: The impacts of carbon footprint tax. Transportation Research Part E: Logistics and Transportation Review, $55,43-54$.

Choi, T.-M., 2013b. Optimal apparel supplier selection with forecast updates under carbon emission taxation scheme. Computers and Operations Research, 40(11), 2646-2655.

Choi T.-M., 2013c. Carbon footprint tax on fashion supply chain systems. The International Journal of Advanced Manufacturing Technology, 68(1-4), 835-847.

Daskin, M.S., Snyder, L.V. and Berger, R.T., 2003. Facility location in supply chain design. Department of Industrial Engineering and Management Sciences, Northwestern University, Evanston, Illinois 60208-3119, U.S.A., Working Paper No. 03-010.

Daskin, M.S., Snyder, L.V. and Berger, R.T., 2005. Facility location in supply chain design. In: Langevin, A. and Riopel, D. (Eds.), Logistics Systems: Design and Optimization, Springer US, pp 39-65.

Department of Energy \& Climate Change, UK. 2010. Monitoring and Understanding $\mathrm{CO}_{2}$ Emissions from Road Freight Operations.

Department for Environment, Food and Rural Affairs. 2008 Guidelines to Defra's GHG Conversion Factors: Methodology Paper for Transport Emission Factors. London: UK.

Diabat, A, and Govindan, K., 2011. An analysis of the drivers affecting the implementation of green supply chain management. Resources, Conservation and Recycling, 55(6), 659667. 
Derbel, H., Jarboui, B., Chabchoub, H., Hanafi, S. and Mladenovic, N., 2011. A variable neighborhood search for the capacitated location-routing problem. In: Proceedings of the $4^{\text {th }}$ International Conference on Logistics, 31 May-3 June 2011, Hammamet, Tunisia, pp. 514519.

Duhamel, C., Lacomme, P., Prins, C. and Prodhon, C., 2010. A GRASP×ELS approach for the capacitated location-routing problem. Computers \& Operations Research, 37(11), 1912-1923.

Erdoğan, S. and Miller-Hooks, E., 2012. A green vehicle routing problem. Transportation Research Part E: Logistics and Transportation Review, 48(1), 100-114.

Esteco, 2012. modeFRONTIER $^{\mathrm{TM}} 4$ User Manual. URL: http://www.esteco.com/home/mode_frontier/mode_frontier.html, Accessed on 20 October 2012.

Fleischmann, M., Beullens, P., Bloemhof-Ruwaard, J.M. and Van Wassenhove, L.N., 2001. The impact of product recovery on logistics network design. Production \& Operations Management, 10(2), 156-173.

Fortes, J. 2009. Green supply chain management: a literature review. Otago Management Graduate Review, 7, 51-62.

Grenchus, E., Johnson, S., McDonell, D., 2001. Improving environmental performance through reverse logistics at IBM. Proceedings of the 2001 IEEE International Symposium on Electronics and the Environment. 07 May 2001-09 May 2001, pp. 236-240.

Gendreau, M, Hertz, A and Laporte, G., 1994. A tabu search heuristic for the vehicle routing problem. Management Science, 40(10), 1276-1290.

Gungor, A. and Gupta, S.M., 1999. Issues in environmentally conscious manufacturing and product recovery: a survey. Computers \& Industrial Engineering, 36(4), 811-853.

Ghodsi, R. and Amiri, A.S., 2010. A variable neighborhood search algorithm for continuous location routing problem with pickup and delivery. In: Proceedings of the Fourth Asia International Conference on Mathematical/Analytical Modelling and Computer Simulation, 26-28 May 2010, Kota Kinabalu, Malaysia, pp. 199 - 203.

Guide Jr., V.D.R. and Van Wassenhove, L.N., 2009. The evolution of closed-loop supply chain research. Operations Research, 57(1), 10-18.

Guide, V.D.R. and Srivastava, R., 1998. Inventory buffers in recoverable manufacturing. Journal of Operations Management, 16(5), 551-568.

Gunnarsson, H., Rönnqvist, M. and Carlsson, D., 2006. A combined terminal location and ship routing problem. Journal of the Operational Research Society, 57(8), 928-938.

Hassanzadeh A., Mohseninezhad, L., Tirdad, A., Dadgstari, F., and Zolfagharinia, H., 2009. Location-routing problem. In: R.Z. Farahani and M. Hekmatfar (Eds.), Facility Location: 
Concepts, models, algorithms and case studies (Contributions to management science), Springer, pp. 395-417.

Herrero, R., Rodríguez, A., Cáceres-Cruz, J. and Juan, A. A., 2014. Solving vehicle routing problems with asymmetric costs and heterogeneous fleets. International Journal of Advanced Operations Management, 6(1), 58-80.

Hong, I.-H. and Yeh, J.-S., 2012. Modeling closed-loop supply chains in the electronics industry: A retailer collection application. Transportation Research Part E: Logistics and Transportation Review, 48(4), 817-829.

Hwang, H.-S., 2002. Design of supply-chain logistics system considering service level. Computers \& Industrial Engineering, 43(1-2), 283-297.

Hwang, C.L. and Yoon, K., 1981. Multiple attribute decision making. Lecture Notes in Economics and Mathematical Systems, 186, Berlin: Springer-Verlag.

Jacobsen, S.K. and Madsen, O.B.G., 1980. A comparative study of heuristics for a two-level routing-location problem. European Journal of Operational Research, 5(6), 378-387.

Jin, L., Zhu, Y., Shen, H. and Ku, T., 2010. A hybrid genetic algorithm for two-layer location-routing problem. $4^{\text {th }}$ International Conference on New Trends in Information Science and Service Science, 11-13 May 2010, Gyeongju, South Korea, pp. 642 - 645.

Karaoglan, I., Altiparmak, F., Kara, I. and Dengiz, B., 2012. The location-routing problem with simultaneous pickup and delivery: Formulations and a heuristic approach. Omega, 40(4), 465-477.

Karaoglan, I. and Altiparmak, F., 2010. A hybrid genetic algorithm for the location-routing problem with simultaneous pickup and delivery. In: Proceedings of the $40^{\text {th }}$ International Conference on Computers and Industrial Engineering, 25-28 July 2010, Awaji Island, Japan, pp. 1-6.

Kulcar, T., 1996. Optimizing solid waste collection in Brussels. European Journal of Operational Research, 90(1), 71-77.

Laporte, G., 1988. Location-routing problems. In: Golden, B.L., Assad, A.A. (Eds.), Vehicle Routing: Methods and Studies. North-Holland, Amsterdam, pp. 163-198.

Lee, S.-Y., 2008. Drivers for the participation of small and medium-sized suppliers in green supply chain initiatives. Supply Chain Management: An International Journal, 13(3), 185198.

Lin, C.K.Y. and Kwok, R.C.W., 2006. Multi-objective metaheuristics for a location-routing problem with multiple use of vehicles on real data and simulated data. European Journal of Operational Research, 175(3), 1833-1849.

Lin, C.K.Y., Chow, C.K. and Chen, A., 2002. A location-routing-loading problem for bill delivery services. Computers \& Industrial Engineering, 43(1-2), 5-25. 
Liu, H., Wang, W. and Zhang, Q., 2012. Multi-objective location-routing problem of reverse logistics based on GRA with entropy weight. Grey Systems: Theory and Application, 2(2), 249-258.

Lopes, R.B., Barreto, S., Ferreira, C. and Santos, B.S., 2008. A decision-support tool for a capacitated location-routing problem. Decision Support Systems, 46(1), 366-375.

Madsen, O.B.G., 1983. Methods for solving combined two level location routing problems of realistic dimension. European Journal of Operational Research, 12(3), 295-301.

Marinakis, Y. and Marinaki, M., 2008a. A bilevel genetic algorithm for a real life location routing problem. International Journal of Logistics: Research and Applications, 11(1), 4965.

Marinakis, Y. and Marinaki, M., 2008b. A particle swarm optimization algorithm with path relinking for the location routing problem. Journal of Mathematical Modelling and Algorithms, 7(1), 59-78.

Marinakis, Y., Marinaki, M. and Matsatsinis, N., 2008. Honey bees mating optimization for the location routing problem. In: Proceedings of the IEEE International Engineering Management Conference, 28-30 June 2008, Estoril, Portugal, pp. 1-5.

Melechovský, J., Prins, C. and Calvo, R.W., 2005. A metaheuristic to solve a location-routing problem with non-linear costs. Journal of Heuristics, 11(5-6), 375-391.

Min, H., Jayaraman, V. and Srivastava, R., 1998. Combined location-routing problems: a synthesis and future research directions. European Journal of Operational Research, 108(1), $1-15$.

Nagy, G. and Salhi, S., 2007. Location-routing: issues, models and methods. European Journal of Operational Research, 177(2), 649-672.

Neto, J.Q.F., Walther, G., Bloemhof, J., van Nunen, J.A.E.E. and Spengler, T., 2009. A methodology for assessing eco-efficiency in logistics networks. European Journal of Operational Research, 193(3), 670-682.

Nguyen, V.-P., Prins, C. and Prodhon, C., 2012. Solving the two-echelon location routing problem by a GRASP reinforced by a learning process and path relinking. European Journal of Operational Research, 216(1), 113-126.

Noci, G. 1997. Designing 'green' vendor rating systems for the assessment of a supplier's environmental performance. European Journal of Purchasing \& Supply Management, 3(2), $103-114$.

Nylund, N.-O. and Erkkilä, K., 2005. Heavy-duty truck emissions and fuel consumption simulating real-world driving laboratory conditions. In: Presentation on behalf of VTT Technical Research Centre of Finland in the 2005 Diesel Engine Emissions Reduction (DEER) Conference, 21-25 Aug 2005, Chicago, Illinois, USA. 
Or, I. and Pierskalla, W.P., 1979. A transportation location-allocation model for regional blood banking. AIIE Transactions, 11(2), 86-94.

Perl, J. and Daskin, M.S., 1984. A unified warehouse location-routing methodology. Journal of Business Logistics, 5(1), 92-111.

Perl, J. and Daskin, M.S., 1985. A warehouse location-routing problem. Transportation Research Part B: Methodological, 19(5), 381-396.

Prins, C., Prodhon, C. and Calvo, R.W., 2006a. Solving the capacitated location-routing problem by a grasp complemented by a learning process and a path relinking. 4OR: A Quarterly Journal of Operations Research, 4(3), 221-238.

Prins, C., Prodhon, C. and Calvo, R.W., 2006b. A memetic algorithm with population management (MA|PM) for the capacitated location-routing problem. In: Evolutionary Computation Combinatorial Optimization. Lecture Notes in Computer Science, Vol. 3906, pp. 183-194.

Rao, P. and Holt, D., 2005. Do green supply chains lead to competitiveness and economic performance? International Journal of Operations and Production Management, 25(9), 898916.

Reclay Holding GmbH, 2012. Product carbon footprint. URL: http://reclaygroup.com/?id=267\&L=1, Accessed on 15 October 2012.

Russell, R., Chiang, W.C. and Zepeda, D., 2008. Integrating multi-product production and distribution in newspaper logistics. Computers \& Operations Research, 35(5), 1576-1588.

Saaty, T.L., 1977. A scaling method for priorities in hierarchical structures. Journal of Mathematical Psychology, 15(3), 234-281.

Saaty, T. L. 1994. How to make a decision: the analytic hierarchy process. Interfaces, 24(6), $19-43$.

Salimifard, K. and Raeesi, R., 2014. A green routing problem: optimising $\mathrm{CO}_{2}$ emissions and costs from a bi-fuel vehicle fleet. International Journal of Advanced Operations Management, 6(1), 27-57.

Schwardt, M. and Fischer, K., 2009. Combined location-routing problems - a neural network approach. Annals of Operations Research, 167(1), 253-269.

Seuring, S. and Müller, M., 2008. From a literature review to a conceptual framework for sustainable supply chain management. Journal of Cleaner Production, 16(15), 1699-1710.

Srivastava, S.K., 2007. Green supply chain management: a state-of-the-art literature review. International Journal of Management Reviews, 9(1), 53-80.

Stenger, A., Schneider, M., Schwind, M. and Vigo, D., 2012. Location routing for small package shippers with subcontracting options. International Journal of Production Economics, 140(2), 702-712. 
The Irish Co-operative Organisation Society (ICOS). URL: http://www.icos.ie. Visited on 19 October 2012.

Ting, C.-J. and Chen, C.-H., 2013. A multiple ant colony optimization algorithm for the capacitated location routing problem. International Journal of Production Economics, 141(1), 34-44.

Tuzun, D. and Burke, L.I., 1999. A two-phase tabu search approach to the location routing problem. European Journal of Operational Research, 116(1), 87-99.

United Nations Framework Convention on Climate Change, 2012. Emissions trading. URL: http://unfccc.int/kyoto_protocol/mechanisms/emissions_trading/items/2731.php. Accessed on 15 October 2012.

Validi, S., 2014. Low carbon multi-objective location-routing in supply chain network design. Unpublished PhD thesis, Dublin City University Business School.

Validi, S., Bhattacharya, A. and Byrne, P.J., 2014. Integrated low-carbon distribution system for the demand side of a product distribution supply chain: a DoE-guided MOPSO optimiser-based solution approach. International Journal of Production Research, 52(10), 3074-3096.

Validi, S., Bhattacharya, A. and Byrne, P.J., 2012. Greening the Irish food market supplychain through minimal carbon emission: an integrated multi-objective location-routing approach. In: T. Baines, B. Clegg, and D. Harrison (Eds.), Proceedings of the $10^{\text {th }}$ International Conference on Manufacturing Research, Vol. 2, Advances in Manufacturing Technology XXVI, $11-13^{\text {th }}$ September, Birmingham, UK, pp. 805-810.

Walker, H., Sisto, L.D. and McBain, D., 2008. Drivers and barriers to environmental supply chain management practices: Lessons from the public and private sectors. Journal of Purchasing and Supply Management, 14(1), 69-85.

Walton, S.V., Handfield, R.B. and Melnyk, S.A., 1998. The green supply chain: integrating suppliers into environmental management processes. International Journal of Purchasing \& Materials Management, 34(2), 2-11.

Wang, F., Lai, X. and Shi, N., 2011. A multi-objective optimization for green supply chain network design. Decision Support Systems, 51(2), 262-269.

Watson-Gandy, C.D.T. and Dohrn, P.J., 1973. Depot location with van salesmen - a practical approach. Omega, 1(3), 321-329.

Wiedmann, T. and Minx, J., 2008. A definition of 'carbon footprint'. In: C.C. Pertsova, Ecological Economics Research Trends: Chapter 1, pp. 1-11, Nova Science Publishers, Hauppauge NY, USA.

Wu, T.-H., Low, C., Bai and J.-W., 2002. Heuristic solutions to multi-depot location-routing problems. Computers \& Operations Research, 29(10), 1393-1415. 
Yang, P. and Zi-Xia, C., 2009. Two-phase particle swarm optimization for multi-depot location-routing problem. In: Proceedings of International Conference on New Trends in Information and Service Science. Beijing, 30 June-2 July 2009, pp. 240-245.

Yu, V.F., Lin, S.-W., Lee, W. and Ting, C.-J., 2010. A simulated annealing heuristic for the capacitated location routing problem. Computers \& Industrial Engineering 58(2), 288-299.

Zhu, Q., Sarkis, J. and Lai, K.-H., 2008. Green supply chain management implications for closing the loop. Transportation Research Part E: Logistics and Transportation Review, 44(1), 1-18.

Zhou, J. and Liu, B., 2007. Modeling capacitated location-allocation problem with fuzzy demands. Computers \& Industrial Engineering, 53(3), 454-468. 